\title{
MODELIZAÇAO DO CLIMA URBANO DE SANTA MARIA, RS
}

Maria da Graça Barros Sartori

Departamento de Geociências. Centro de Ciências Naturais e Exatas. UFSM. Santa Maria, RS.

RESUMO

A urbanização impõe modificações no clima local comprome tendo a prōpria atmosfera da cidade e originando o clima urbano. Bus cando verificar a existência de clima urbano em Santa Maria, foram realizadas anālises climäticas de temperatura, vento e umidade rela tiva atravēs de dados coletados em trabalho de campo e em estação meteorolögica, associadas as da circulação atmosférica regional. os resultados obtidos e os exemplos contidos na literatura nacional e internacional, somados à anālise das componentes geoecológicas e geo urbanas locais, possibilitaram uma proposta de modelização de clima urbano para Santa Maria, localizada na região central do Estado do Rio Grande do Sul, Brasil.

\section{SUMMARY}

BARROS SARTORI, M.G., 1986. Simulating model of the urban climate of Santa Maria, RS. Ciência e Natura, 8:53-65.

Urbanization causes changes in the local climate by altering the atmosphere of a city and creating the urban climate. Attempting to verify the existence of urban climate in Santa Maria, climatic analysis was made of temperature, wind and relative humidity of data gathered in the field as well as from the meteorological station, in relaction to the regional atmospheric circulation analysis.

The results of this study and samples from national and international finding, together with the local analysis of geoecological and geourban components, help in presenting a simulating model of the urban climate of Santa Maria located in the center of the State of Rio Grande do Sul, Brazil.

INTRODUÇÃO

E ainda dificil de se determinar a que grau de urbaniza ção corresponderia um clima tipicamente urbano. Santa Maria, local zada na região central do Estado do Rio Grande do Sul, Brasil (Figu ra 1), com sua categoria atual de cidade de porte médio, jā possibi litaria a definição de um clima urbano?

o clima urbano é, segundo MONTEIRO (6),

"...um Clima Local Modificado. O processo de im plantação urbana sobre um dado lugar do espaço geogräfico cria novas formas e impõe uma estru tura fisica característica, a qual suas atividā des e funçōes atingem os mais altos graus de 
alteração humana no espaço geogräfico, capaz de comprometer a prōpria atmosfera."

Isto significa que muitas são as componentes internas da cidade que se integram e interferem no quadro climático local alte rando-o e dando origem a atributos específicos que configuram um cl $\underline{i}$ ma urbano.

Assim, o clima urbano, de acordo com o tamanho da cidade, e tratado nas escalas de Mesoclima e Topoclima (MONTEIRO, 6) tendo como fatores principais a compartimentação geoecológica e geourbana, em associação. Não obstante, deve-se considerar sua vinculação ao clima regional definido pela circulação atmosférica e fatores geo gräficos regionais, responsāveis pela sucessão de tipos de clima.

As peculiaridades desse nīvel climätico e as nossas limi tações de anālise são muitas. A observação necessāria à revelação dos atributos urbanos requer trabalho de campo e instrumentos ade quados.

A rede de observação meteorolōgica padronizada persegue o comportamento do ar livere, necessārio à anālise da Circulação Regio nal e das respostas a nivel local. Apenas os registros especialmen te conduzidos dentro da cidade são capazes de captar a influência das componentes urbanas.

A necessidade de observações especiais dentro da cidade deve-se ao fato de que a, urbanização altera o espaço físico-natural por tornar os solos impermeāveis e a atmosfera contaminada por ga ses e particulas sōlidas, por alterar o fluxo de ar que se canaliza pelas ruas e edifỉcios, por aumentar a absorção de energia térmica, por eliminar a cobertura vegetal.

Ao considerarmos o ritmo de crescimento de Santa Maria e os problemas resultantes do processo de urbanização e da conseqüen te adição de novos componentes ao nücieo urbano, resolvemos real $\underline{j}$ zar testes experimentais, pelo menos de temperatura, a fim de ver $\underline{j}$ ficarmos se jā se configurava algum efeito da ilha de calor, prime $\underline{j}$ ro sintoma da existência de um clima urbano.

Alēm disso, o efeito ilha de calor da cidade é fundamen tal e condição suficiente à geração de uma ventilação especificamen te urbana que, junto com as alterações no comportamento dos demais elementos do clima, gera uma atmosfera própria da cidade.

BASES A PROPOSTA DE CLIMA URBANO PARA SANTA MARIA

Com base nas anālises climāticas realizadas por BARRos SARTORI ( 1 e 3) em 1979 e 1984, somadas à revisão bibliográfica so bre clima urbano que nos forneceu os fatos legalizados sobre o as sunto, tentamos montar um modelo de clima urbano para Santa Maria.

0 modelo é representado por um desenho esquemático (Figura 2) 
e se constitui num projeto experimental que servirá, principalmente, de apoio à futuras investigações. Os critérios adotados para a ela boração deste desenho foram a simplificação, a geometria e a genera 1 ização dos elementos representados.

Nossa intenção não é, de māneira alguma, propor essa mode 1 ização como definitiva, visto que as precárias observações que rea 1 izamos, em 1979, a nível urbano não nos permitiram comprovā-la.

Entretanto, muitas são as componentes geoecológicas e geo urbanas de Santa Maria que sugerem a existência de clima urbano ca racterístico. Na comprovação deste fato, são necessārias observações mais específicas e detalhadas a nīvel urbano, o que será objeto de futuros estudos.

No momento, pretendemos apenas sugerir, através do refer $\underline{i}$ do desenho, o que poderá ser o clima urbano santamariense, com base nos fatos referidos na literatura internacional sobre o assunto.

A primeira condição para existir o clima urbano é a exis tência da ilha de calor na cidade, jā que, a partir dela e dos de mais componentes geoecológicos e geourbanos locais, define-se o com portamento dos demais elementos atmosféricos que caracterizam o cl $\underline{i}$ ma, tais como: pressão, vento, umidade, nebulosidade, precipitação, entre outros.

Numa primeira tentativa, para detectar o efeito da ilha de calor em Santa Maria, partimos de trabalho de campo realizado du rante os dias 19,20 e 21 de março de 1979 (BARROS SARTORI, 1, pp. $139-146)$.

0 trabalho constou da medida da temperatura ambiente em trés pontos diferentes da cidade, utilizando termômetros a àlcool, marca INCOT்ERM, em horārias oficiais de observação meteorológica do Instituto Nacional de Meteorologia que são: 09:00, 15:00 e 21:00 ho ras.

Os locais foram selecionados em função de ambientes que melhores respostas poderiam fornecer em relação ao centro da cidade, tendo sido escolhidos:

- centro da cidade, no Calçadão da Rua Dr. Bozano;

- dependēncias do Regimento Mallet do Exērcito, à oeste da zona central urbana;

- pátio da Casa de Retiros, à sudeste do centro da cidade.

Nesses três pontos de observação, os termōmetros foram instalados à sombra, mais ou menos a um metro do chão, e protegidos do vento.

Enquanto no calçadão as medidas foram realizadas num am biente cercado de edificios e com grande movimento de pessoas, no Regimento Mallet os dados foram obtidos na portaria de recepção e na Casa de Retiros, no pātio sob as ārvores. 
Como pretendíamos associar a temperatura com a umidade re lativa, utilizamos dois termómetros para cada local e colocamos, num deles, um chumaço de algodão embebido d'água, a fim de torná-lo ter mómetro de bulbo úmido. A diferença de temperatura entre o seco e o úmido nos permitiu obter o valor da Umidade Relativa para cada am biente.

Os resultados da observação simultânea da temperatura nos trēs ambientes urbanos acima mencionados constam da Tabela I, conju gados aos da estação meterológica, instalada no campus da UFSM, pa ra efeito de comparação.

Tendo em vista que o efeito da izha de calor é melhor observa do em condições especiais de tempo, tivemos que aguardar a ocasião mais propicia para realizarmos o trabalho de campo.

Nas fases pré-frontais a circulação regional controlada por um outro sistema atmosférico se acentua, devido ao processo de aquecimento sobre o continente (especialmente no verão), e isto for nece a individualização da itha de calor.

Por essa razão, os dias escolhidos foram aqueles em que os ventos eram fracos, numa fase pré-frontal e com grande aquecimen to.

As condições de tempo durante o trabal ho de campo refleti ram o comportamento da circulação atmosférica regional que determi nava uma situação tipicamente pré-frontal para o Rio Grande do Sul, entre os dias 19 e 21 de março de 1979, conforme Figura 1 .

Assim, a época escolnida e o tipo de tempo dominante (Tem po Anticiclōnico Polar em Tropicalização, segundo caracterỉsticas a presentadas em BARROS SARTORI, 2) foram definidos como ideais para permitir a observação do efeito "ilha de calor" na cidade, jā que de acordo con OBE (1982), citado em LOMBARDO (5), nas cidades de clima temperado a maior frequéncia da ilha de calor é no verão e no outono.

As respostas da cidade às condições de tempo dominantes fo ram facilmente detectadas no trabal ho de campo.

Conforme mostra a Tabela I, o centro da cidade (Calçadão), com sua complexidade estrutural e de circulação, foi onde registra ram-se as maiores temperaturas e, consequentemente, as percentagens mais baixas de Umidade Relativa do ar. Assim, ao compararmos o cen tro intraurbano com os outros dois ambientes urbanos (Regimento Mallet e Casa de Retiros), verifica-se de imediato as diferenças de temperatura e, por extensão, as de Umidade Relativa.

As 09:00 horas e às 21:00 horas a amplitude térmica entre - centro e os pontos periféricos são bem menores que aquela das 15:00 horas. Justifica-se este fato pelas trocas térmicas mais acen tuadas no centro urbano impostas pelas edificações, circulação e 

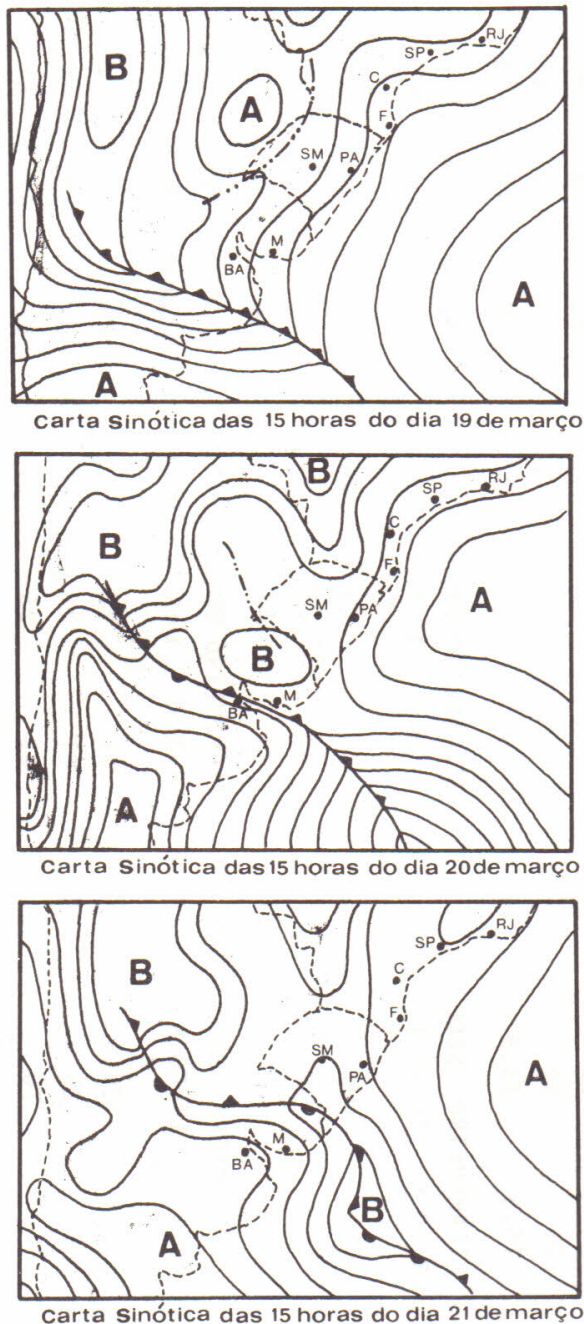

Figura 1 - A Circulação Secundāria Regional, no sudeste da América do Sul, durante o trabalho de campo, de 19 a 21 de março de 1979.

Legenda:

A Alta Pressão

B Eaixa Pressão

Frente Fria

Wrente Quente

T. Frente Estacionária

RJ - Rio de Janeiro

PA - Porto Alegre

SP - São Paulo

SM - Santa Maria

C - Curitiba

M - Montevideo

F - Florianópolis

BA - Buenos Aires 
TABELA I - COMPARAÇÃO SIMULTĀNEA DA TEMPERATURA ENTRE TRES AMBIENTES NO NOCLEO URBANO DE SANTA MARIA E A ESTAÇAO METEOROLOGICA INSTALADA NO CAMPUS DA U.F.S.M.

\begin{tabular}{|c|c|c|c|c|c|c|c|c|c|}
\hline CALÇADÃO (NO CENTRO) & TERMŌM & TRO SECO & $\left({ }^{0} \mathrm{C}\right)$ & TERMŌME & RO OMIDO & $\left({ }^{0} \mathrm{C}\right)$ & \multicolumn{3}{|c|}{ UMIDADE RELATIVA (\%) } \\
\hline Dias & 09:00 h & $15: 00 \mathrm{~h}$ & $21: 00 \mathrm{~h}$ & $09: 00 \mathrm{~h}$ & $15: 00 \mathrm{~h}$ & $21: 00 \mathrm{~h}$ & $09: 00 \mathrm{~h}$ & $15: 00 \mathrm{~h}$ & $21: 00 \mathrm{~h}$ \\
\hline 19 de março & 26 & 31 & 27 & 21 & 23 & 22 & 67 & 53 & 67 \\
\hline 20 de março & 26 & 32 & 27,5 & 20,5 & 23,5 & 22,5 & 54 & 60 & 67 \\
\hline 21 de março & 25,5 & 33,5 & 27 & 21,5 & 23,5 & 20,5 & 70 & 42 & 50 \\
\hline GRUPO MALLET & TERMÔM & TRO SECO & $\left({ }^{\circ} \mathrm{C}\right)$ & TERMÖME & RO OMIDO & $\left({ }^{\circ} \mathrm{C}\right)$ & UMIDADE & E RELATIV & VA $(\%)$ \\
\hline Horas & 09:00 h & $15: 00 \mathrm{~h}$ & $21: 00 \mathrm{~h}$ & 09:00 h & $15: 00 \mathrm{~h}$ & $21: 00 \mathrm{~h}$ & $09: 00 \mathrm{~h}$ & $15: 00 \mathrm{~h}$ & $21: 00 \mathrm{~h}$ \\
\hline 19 de março & 25 & 29 & 27 & 22 & 26 & 25 & 77 & 79 & 85 \\
\hline 20 de março & 25 & 28 & 26 & 23 & 25 & 24 & 84 & 78 & 85 \\
\hline 21 de março & 24 & 29 & 26 & 23 & 24 & 23 & 92 & 66 & 78 \\
\hline CASA DE RETIROS & TERMÖM & TRO SECO & $\left({ }^{0} \mathrm{C}\right)$ & TERMÖME & RO OMIDO & $\left({ }^{0} \mathrm{C}\right)$ & UMIDADE & E RELATIV & $V A(\%)$ \\
\hline Horas & $09: 00 \mathrm{~h}$ & $15: 00 \mathrm{~h}$ & $21: 00 \mathrm{~h}$ & 09:00 h & $15: 00 \mathrm{~h}$ & $21: 00 \mathrm{~h}$ & $09: 00 \mathrm{~h}$ & $15: 00 \mathrm{~h}$ & $21: 00 \mathrm{~h}$ \\
\hline 19 de março & 26 & 29,5 & 24 & 23 & 26 & 22 & 78 & 76 & 84 \\
\hline 20 de março & 22 & 25 & 26 & 21 & 22 & 24 & 92 & 77 & 85 \\
\hline 21 de março & 24 & 30 & 26 & 22 & 25 & 21 & 84 & 67 & 64 \\
\hline ESTAÇĀO METEOROLŌGICA & TERMŌM & TRO SECO & $\left({ }^{0} \mathrm{C}\right)$ & TERMŌME & RO OMIDO & $\left({ }^{0} \mathrm{C}\right)$ & UMIDADE & E RELATIV & $V A(\%)$ \\
\hline Horas & $09: 00 \mathrm{~h}$ & $15: 00 \mathrm{~h}$ & $21: 00 \mathrm{~h}$ & $09: 00 \mathrm{~h}$ & $15: 00 \mathrm{~h}$ & $21: 00 \mathrm{~h}$ & $09: 00 \mathrm{~h}$ & $15: 00 \mathrm{~h}$ & $21: 00 \mathrm{~h}$ \\
\hline \multicolumn{10}{|l|}{ Dias } \\
\hline 19 de março & 21,8 & 30,6 & 24 & 20 & 24,2 & 21,7 & 82 & 53 & 81 \\
\hline 20 de março & 23 & 31 & 23,4 & 20,6 & 24,2 & 21,8 & 80 & 60 & 88 \\
\hline 21 de março & 22,6 & 31,2 & 23,8 & 20,3 & 24,8 & 21,9 & 80 & 59 & 84 \\
\hline
\end{tabular}


pavimentação das ruas, que absorvem ou refletem a radiação recebida transmitindo calor ao ambiente e favorecendo o aumento da temperatu ra.

Entretanto, o centro da cidade sempre registra valores têr micos mais elevados nos trēs horārios de observação, variando ape nas o indice minimo de diferença entre os ambientes urbanos.

observa-se, por exemplo, na Tabela I que às 09:00 horas e às 21:00 horas as diferenças de temperatura são de $1,0{ }^{\circ} \mathrm{C}$ a $4,0{ }^{\circ} \mathrm{C}$ e de $1,0{ }^{\circ} \mathrm{C}$ a $1,5{ }^{\circ} \mathrm{C}$ entre o Calçadão e a Casa de Retiros e o Regi mento Mallet, respectivamente.

As 15:00 horas as diferenças aumentam ficando entre $2,0^{\circ} \mathrm{C}$ e $4,5{ }^{\circ} \mathrm{C}$ (Regimento Mallet) e 2,5 a $7,0{ }^{\circ} \mathrm{C}$ (Casa de Retiros).

os valores da umidade relativa nos três ambientes refle tem as condições de maior aquecimento e secura do ar no centro da cidade, chegando aos $42 \%$ às 15:00 horas do dia 21 de março.

Como aconteceu com a temperatura, é o centro da cidade que fica com os indices mais baixos de Umidade Relativa jă que ela re flete o comportamento da temperatura e da evaporação. Por essa ra zão, as condições de tempo da fase pré-frontal acentuou os valores baixos das 15:00 horas nos três locais de observação, principalmen te no dia 21 .

Mesmo assim, as diferenças māximas de umidade relativa fọ ram, pela ordem de horārio (09:00, 15:00 e 21:00 horas), de 38\%, 25\% e $18 \%$ e de $30 \%, 26 \%$ e $28 \%$ entre o centro da cidade e a Casa de Reti ros e o Regimento Mallet, respectivamente.

Para a caracterização do efeito ilha de calor urbana, com paramos as temperaturas registradas na cidade com as do posto meteo rológico instalado no Campus da UFSM, longe de qualquer interferēn cia urbana, refletindo, portanto, as condições das circunvizinhan ças, principalmente nas medidas das 09:00 horas e das 21:00 horas ( Tabela I).

Segundo trabalhos realizados nos Estados Unidos e na Eu ropa, è pela manhã e à noite que mais facilmente se observa a ilha de calor urbana devido o resfriamento mais rāpido da superfỉcie no meio rural. Os dados de temperatura que constam da Tabela I confir mam este fato, pois nos referidos horārios as temperaturas do posto meteorolōgico (ar livre) são, nos trēs dias, inferiores as de qual quer um dos locais da àrea urbana.

As 09:00 horas da manhã, observa-se uma amplitude tērmica entre o centro da cidade e o citado posto de $2,9{ }^{\circ} \mathrm{C}$ a $4,2{ }^{\circ} \mathrm{C}$ e às 21:00 horas $3,0{ }^{\circ} \mathrm{C}$ a $4,1{ }^{\circ} \mathrm{C}$, confirmando o resfriamento noturno mais acentuado nas circunvizinhanças da cidade. Os outros do is ambientes urbanos (Regimento Mallet e Casa de Retiros) tambēm têm temperatu ras mais elevadas nestes horārios (Tabela I). 
BORNSTEIN (1968), citado em LOMBARDO (5), analisou o ba lanço de energia na região rural e urbana de Nova York e verificou que na região urbana o calor conduzido pelos edifícios era maior à noite.

A intensidade da ilha de calor pode ser determinada por parâmetros que foram apontados por MYRUP (1969), referido por LOM BARDO (5), como sendo:

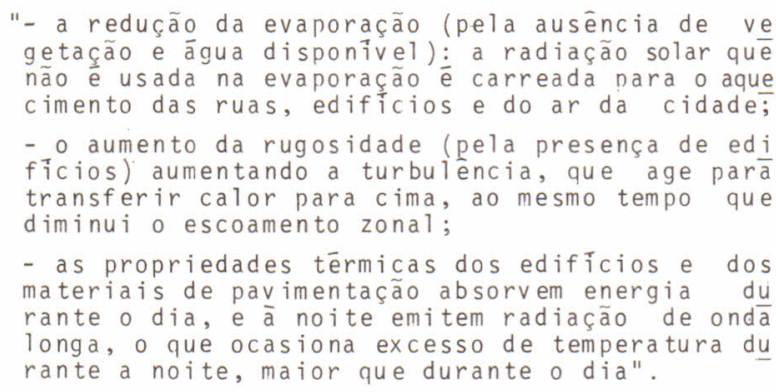

Já KRATZER (1956), também citado por LOMBARDO (5) credita a ilha de calor ao efeito de poluição do ar na cidade que absorve e reirradia ondas de calor, provocando o excesso de temperatura obser vado à noite.

DETWYLER \& MARCUS (4) sintetizam essas colocações afirman do que os materiais densos e artificiais da cidade conseguem armaze nar mais a radiação recebida durante o dia, multiplicando as trocas; à noite estes materiais liberam o calor proveniente da radiação aque cendo o ambiente urbano. No meio rural, ao contrário, o calor é uti lizado para a evaporação durante o dia pouco restando para aquecer o ar à noite.

A diversidade de materiais e de atividades humanas nas ci dades provoca variações nas condições ambientais devido as diferen ças qualitativas na capacidade de absorver e refletir a energia so lar incidente e aquela gerada pela atividade urbana.

Assim, a cidade mantēm mais a temperatura que o meio ru ral e para provā-10 basta verificarmos as amplitudes térmicas entre o centro da cidade e o posto meteorológico nos três horários que constam da Tabela I.

No centro de Santa Maria, a amplitude máxima registrada en tre 09:00 horas e 15:00 horas foi $8,0{ }^{\circ} \mathrm{C}$ e no posto meteorológico foi $9,0{ }^{\circ} \mathrm{C}$ (dia 21), enquanto as diferenças entre às 15:00 horas e às 21:00 horas foi de $6,5{ }^{\circ} \mathrm{C}$ no centro contra $7,4{ }^{\circ} \mathrm{C}$ na periferia (Cam pus da UFSM).

A tarde (15:00 horas), as diferenças de temperatura entre - centro da cidade e a estação meteorológica no Campus da UFSM fó ram menores que as dos outros horārios, tendo sido a máxima de $2,3^{0} \overline{\mathrm{C}}$ 
dia 21. Este fato é em parte explicado pela quantidade de radiação recebida que é praticamente a mesma nos dois locais. A estrutura da cidade apenas contribui para elevar a temperatura.

Estas observações de campo confirmaram a elevação de tem peratura na cidade e a existēncia de Il ha de Calor urbana em Santa Maria, porém não foram suficientes para traçar isotermas que poss $\underline{i}$ bilitassem a determinação das variações tēmporo-espaciais da tempe ratura. Assim a ilha de calor não foi delineada, nem era nosso obje tivo.

Por outro lado, sabe-se que a ilha de calor acompanha a forma do centro da cidade porém com certo deslocamento devido ao vento predominante e a compartimentação geomorfológica do sîtio ur bano. Por isso sua forma é variāvel de cidade para cidade e desloca da em relação ao contorno do centro urbano.

A ilha de calor provoca de imediato alteração do campo de pressão dentro e na periferia da cidade.

Como o ar se movimenta pelas diferenças de pressão e aque cimento, a ilha de calor da cidade gera ārea de baixa pressão no centro que atrai o fluxo de ar da periferia onde as pressões se man tém mais elevadas, devido ao menor aquecimento, influindo nos pa drões da ventilação local. Este fato jä foi analisado por BARROS SAR TORI (3) com vārias considerações relativas a ārea urbana de Santa Maria.

MODELIZAÇÃO DO CLIMA URBANO DE SANTA MARIA

Analisando o modelo proposto que constitui a Figura 2, ve rifica-se que o centro geométrico da cidade está representado pela Praça Saldanha Marinho, a qual não corresponde ao centro urbano pro priamente dito que se expandiu mais para oeste, impedido de se de senvolver para leste pela presença do Arroio Itaimbē que, até 1980, não havia sido ainda canalizado e urbanizado. Hoje, ali encontra-se - Centro Administrativo Municipal e o Parque Itaimbé.

No centro urbano é onde se concentra o maior número de edificios, com desenvolvimento vertical significativo e alta densi dade populacional, com ruas asfaltadas e intensa movimentação de trāfego. E a principal ārea comercial e é este setor urbano que ge ra a provāvel ilha de calor de Santa Maria (Figura 2 - perfis $A-A^{\prime}$ e B-B') cujo efeito detectamos no trabalho de campo.

A partir do circulo central, representativo do centro ur bano, se alongam tỉpicos eixos comerciais que coincidem com as arté rias de maior circulação de veículos fora do centro. Esses eixos apa recem em torno do centro e tem a mesma orientação das principais vias pūblicas.

Mais ou menos contornando a área urbana propriamente dita, 
destaca-se um cīrculo exterior que representa a ārea residencial in discriminada, a partir do qual surgem alguns setores definidos como eixos de crescimento urbano atual. Os dois principais setores (a sul e a leste) se desenvolvem ao longo das rodovias mais importantes que chegam a Santa Maria.

o círculo exterior não se completa para norte e sudeste porque o organismo urbano foi impedido de crescer nestas direções pela presença do rebordo do Planalto e dos morros testemunhos. Por outro lado, o Arroio Cadena a oeste, evita a ocupação mais efetiva de sua vārzea devido aos problemas oriundos das inundações em épocas de fortes ou prolongadas chuvas.

Assim, a cidade ocupa ārea do festão colinoso da serra, de acordo com BARROS SARTORI (1), sem muita opção para seu cresc $\underline{i}$ mento, desenvolvendo-se ao longo das rodovias, onde a topografia per mite a ocupação.

Com o tipo de sitio e estrutura urbana, jā definidos por BARROS SARTORI (1), presumimos que muitos serão os problemas que ad virão do mau uso do solo urbano se forem desconsiderados os atribu tos climáticos locais.

Em 1979 e 1984, determinamos que os ventos mais importan tes em Santa Maria são os de leste(predominantes em frequência), os de norte e noroeste (mais quentes e de maior velocidade) e os de sul e sudeste (mais frios e segundos em frequência).

A topografia mais elevada da ārea urbana, representada pe 10 Planalto e seus morros testemunhos, são responsāveis pela canali zação do vento em direção à cidade, auxiliando na predominância dos ventos de leste, já que o rebordo do referido planalto alonga-se no sentido leste-oeste. Os ventos de leste são secundados pelos ventos de sudeste, em parte freados no seu deslocamento pelos morros teste munhos posicionados à leste e sudeste da cidade.

os fluxos de ar mais intensos são os de norte e noroeste das fases pré-frontais que ao descerem o rebordo do Planalto (Figu ra 2 - perfil B-B'), com desnível de mais de 250 metros, sofrem o efeito "Föehn" acelerando-se, aquecendo-se e ressecando o ar.

Somada à influência da topografia, a orientação das ruas que pode ser observada pelo traçado das vias de maior circulação (Figura 2), favorecem a entrada na cidade dos ventos acima menciona dos.

Em trabalho que apresentamos em 1984 (BARROS SARTORI, 3) analisamos esses aspectos relacionados à ventilação urbana de Santa Maria, salientando a influéncia exercida pela urbanização e topogra fia no fluxo de ar que se desloca sobre a cidade e por ela determi nada.

Neste aspecto de ventilação, ressaltamos que o Distrito 
Industrial de Santa Maria, localizado a WNW da cidade, poderá, no futuro, eventualmente acarretar problemas de poluição para a ārea urbana. E preciso deixar claro que sua localização é boa, se consi derarmos a direção do vento predominante (leste), mas nas ocasiões em que soprarem os ventos de oeste e noroeste as emissões das in dūstrias se dirigirão à cidade (Figura 2 - perfil A-A'). Portanto, é prudente para Santa Maria que as indūstrias que ali venham a se instalar sejam alertadas e orientadas no sentido de evitarem as emis sões, caso sua produção provoque o lançamento de poluentes no ar.

A provāvel ilha de calor de Santa Maria deve mais ou menos coincidir com o centro urbano, porém um pouco deslocada para oeste devido ao vento leste que é o de maior participação na área. No tra balho de campo que realizamos ficou constatado unicamente seu efei to, uma vez que nas condições de observação não nos foi possível de lineá-1a em toda a sua extensão.

Como o maior aquecimento intra-urbano, provocado pelas tro cas térmicas mais intensas entre os materiais que compõem a estrutu ra da cidade, é responsāvel pela formação de ārea de baixa pressão, o conhecimento desse fato torna-se fundamental pois dele resulta a geração de uma ventilação urbana especîfica.

Alēm disso, as temperaturas mais elevadas do centro intra urbano originam movimentos convectivos do ar (Figura 2 - perfis $A-A^{\prime}$ e $B-B^{\prime}$ ) que serão tanto mais acentuados quanto maior for a concentra ção de edifícios e, consequentemente, mais intensa a ilha de calor.

A ausência de āreas verdes no núcleo da cidade tambēm nos parece ser problema agravente para originar em Santa Maria um clima urbano acentuado, jā que a vegetação fornece umidade ao ar pela eva potranspiração, diminuindo a temperatura nas suas vizinhanças.

Neste aspecto, as ūnicas āreas verdes que aparecem no sỉ tio urbano de Santa Maria se localizam na encosta do Planalto e nos morros testemunhos, se bem que estejam sendo gradativa e indiscrimi nadamente eliminadas com o passar do tempo por desmatamento, o que agravará cada vez mais as condiçöes ambientais. (Figura 2).

Concluindo, embora as limitações dos resultados apresenta dos neste trabalho, os principais aspectos que podem originar um clima urbano específico, analisados até aqui, permitiram numa fase preliminar, o estabelecimento de um modelo experimental para inves tigações futuras do clima urbano da cidade de Santa Maria.

AGRADECIMENTOS

A Professora Margarete Schlatter do Departamento de Le tras Estrangeiras e Modernas e ao Professor 01 avo Jose Bortolotto do Departamento de Geociēncias da UFSM, pelo auxỉlio prestado na ela boração e revisão do Summary deste trabalho. 


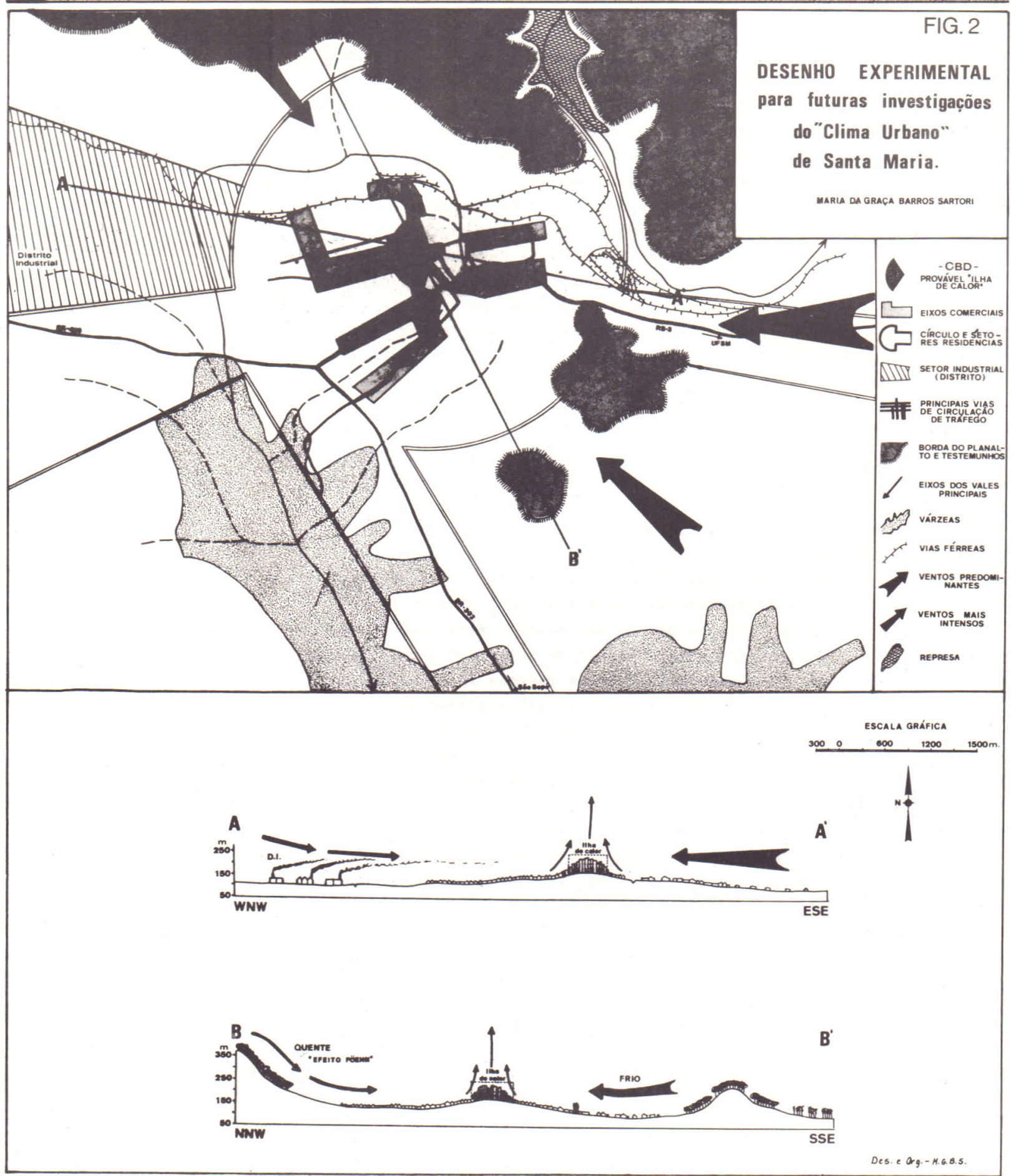




\section{REFERENCIAS BIBL IOGRAFICAS}

1. BARROS SARTORI, Maria da Graça. O Clima de Santa Maria: do regio nal ao urbano. Dissertação de Mestrado, Dep. de Geografia da Fac. de Filosofia, Letras e Ciências Humanas da Universidade de São Paulo. São Paulo, 1979. 169 p.

2. BARROS SARTORI, Maria da Graça. A Circulação Atmosférica Regional e as famîlias de tipos de tempo na região central do Rio Gran de do Sul. Ciência e Natura, Santa Maria, 3:101-110, 1981.

3. BARROS SARTORI, Maria da Graça. Considerações sobre a ventilação nas cidades e sua importāncia no planejamento urbano. Ciência e Natura, Santa Maria, 6:59-74, 1984.

4. DETWYLER, T. \& MARCUS, M.G. Urbanization and Enrironment: the physical Geography of city. Belmont, California, Duxbury, 1972.

5. LOMBARDO, M.A. I Zha de Calor nas Metrópoles: O Exemplo de São Pau 2o. São Paulo, Ed. Hucitec, 1985.

6. MONTEIRo, C.A. de F. Teoria e Clima Urbano. São Paulo, Instituto de Geografia da USP, 1976. Sērie Teses e Monografias 25.

Recebido em dezembro, 1986; aceito em dezembro, 1986. 
